\title{
Reduced expression of DENND2D through promoter hypermethylation is an adverse prognostic factor in squamous cell carcinoma of the esophagus
}

\author{
SOKI HIBINO, MITSURO KANDA, HISAHARU OYA, HIDEKI TAKAMI, \\ DAI SHIMIZU, SHUJI NOMOTO, MITSUHIRO HISHIDA, YUKIKO NIWA, MASAHIKO KOIKE, \\ SUGURU YAMADA, YOKO NISHIKAWA, MIKAKO ASAI, GORO NAKAYAMA, TSUTOMU FUJII, \\ HIROYUKI SUGIMOTO, MICHITAKA FUJIWARA and YASUHIRO KODERA \\ Department of Gastroenterological Surgery (Surgery II), Nagoya University \\ Graduate School of Medicine, Nagoya 466-8550, Japan
}

Received September 14, 2013; Accepted October 25, 2013

DOI: $10.3892 /$ or.2013.2901

\begin{abstract}
Esophageal cancer ranks sixth in cancer mortality worldwide and patients with esophageal squamous cell carcinoma (ESCC) have a poor prognosis with a 5-year survival rate of less than $10 \%$. Elucidation of the mechanisms of carcinogenesis and tumor progression in esophageal cancer is urgently required to develop targets for therapy and prognostic biomarkers. In the present study, the expression and regulatory mechanism of the differentially expressed in normal and neoplastic cells domain containing 2D (DENND2D), which is a regulator of Rab GTPases, were investigated to explore its potential as a tumor suppressor gene for ESCC. The level of DENND2D mRNA expression in ESCC cell lines and surgical specimens was determined using a quantitative real-time reverse transcription-polymerase chain reaction assay, and the relationship between the expression levels of DENND2D mRNA and clinicopathological factors was evaluated. The expression and distribution of DENND2D were determined using immunohistochemistry. DNA methylation analysis was performed to determine the regulatory mechanism of DENND2D expression in ESCC. The level of DENND2D mRNA expression was reduced in 8/9 ESCC cell lines and in 59/65 surgical specimens, and the mean expression levels were significantly lower in cancerous tissues compared to corresponding normal tissues $(\mathrm{P}<0.001)$. The expression pattern of DENND2D protein and mRNA was consistent. Downregulation of DENND2D mRNA in ESCC tissues was
\end{abstract}

Correspondence to: Dr Mitsuro Kanda, Department of Gastroenterological Surgery (Surgery II), Nagoya University Graduate School of Medicine, 65 Tsurumai-cho, Showa-ku, Nagoya 466-8550, Japan

E-mail: m-kanda@med.nagoya-u.ac.jp

Key words: esophageal cancer, DENND2D, expression, DNA methylation, tumor suppressor identified as an independent prognostic factor in multivariate analysis (Hazard ratio, 2.194; $\mathrm{P}=0.039$ ). The DENND2D promoter was methylated in 5/9 ESCC cell lines, and DNA demethylation reactivated DENND2D mRNA expression. Hypermethylation of DENND2D was frequently detected in ESCC tissues $(64.6 \%)$ and was significantly associated with downregulation of DENND2D mRNA expression ( $\mathrm{P}=0.008)$. Taken together, our data suggest that DENND2D is a candidate tumor suppressor gene that was inactivated by promoter hypermethylation in patients with ESCC and may serve as a novel biomarker of ESCC.

\section{Introduction}

Esophageal cancer is the eighth most common cancer and ranks sixth in cancer mortality worldwide (1). It is generally diagnosed at a late stage and has a poor prognosis, with a 5-year survival rate of $<10 \%$ (2). Esophageal squamous cell carcinoma (ESCC) comprises a majority of esophageal cancer in Japan (1). Despite improved multimodal treatment, prognosis remains unsatisfactory, as effective systemic therapy has not been established for patients with advanced ESCC (3). Therefore, investigations that clarify the mechanisms of carcinogenesis and tumor progression in ESCC are urgently required to develop targets for therapy and prognostic biomarkers.

It is well known that carcinogenesis of ESCC can be induced by external factors such as alcohol and smoking. Genetically, aberrant expression of tumor suppressor genes and oncogenes coordinately contribute to carcinogenesis and progression of ESCC. Epigenetic alterations, including promoter hypermethylation, play an important role in downregulating suppressor genes (4-6). In particular, dysfunction of membrane trafficking proteins is essential for cancer progression as it can promote cells to be stimulated by various growth factors and to become chemoresistant $(7,8)$.

Differentially expressed in normal and neoplastic cells (DENN)-domain proteins regulate Rab GTPases and represent a newly recognized class of membrane trafficking 
proteins (9-13). Rab GTPases are members of the Ras family of small GTPases and almost $70 \mathrm{Rab}$ and Rab-like proteins are encoded by the human genome (14). Rab family proteins are important in regulating signal transduction and cellular processes such as differentiation, proliferation, vesicle transport, nuclear assembly, and cytoskeleton formation and some Rab proteins have been reported to be necessary for the adhesion and migration of cancer cells $(15,16)$. The DENN domain present in members of the connecdenn family of proteins interacts directly with Rab35 and functions as a guanine nucleotide exchange factor (GEF) for this GTPase (17). GEFs activate Rabs by mediating the exchange of GDP for GTP. The human genome encodes eight DENND (DENN domain) proteins that form eight families based on homology and domain structure as follows: DENND1A-1C, DENND2A-2D, DENND3, DENND4A-4C, DENND5A/5B, DENND6A/6B, MTMR5/13 and DENN/MADD. The DENN domain is located towards the $\mathrm{N}$-terminus, except in the DENND2 family, where it is located towards the C-terminus (18-21).

Little is known about the function and expression patterns of DENND family proteins in malignant tumors, although they play important roles in intracellular signaling pathways by integrating the activity of Rab pathways. DENND2D, which is located on chromosome $1 \mathrm{p} 13.3$, encodes a $53-\mathrm{kDa}$ protein, which suppresses the proliferation and tumorigenicity of non-small cell lung cancer cells $(20,22)$; however, the role of DENND family proteins in gastroenterological cancer has not been reported. Accordingly, we focused on DENND2D and investigated the regulation of its expression in an attempt to identify a tumor suppressor gene (TSG) regulated by silencing through promoter hypermethylation in ESCC.

\section{Materials and methods}

Ethics statement. The present study conformed to the ethical guidelines of the World Medical Association Declaration of Helsinki-Ethical Principles for Medical Research Involving Human Subjects. Written informed consent for usage of clinical samples and data, as required by the institutional review board at Nagoya University, Japan, was obtained from all patients.

Sample collection. Nine ESCC cell lines (TE1, TE2, TE3, NUEC1, NUEC2, NUEC3, TT, TTn and WSSC) were obtained from the American Type Culture Collection (ATCC, Manassas, VA, USA) or from Nagoya University, Japan, stored at $-80^{\circ} \mathrm{C}$ with cell preservative solution (Cell Banker ${ }^{\circledR}$; Mitsubishi Chemical Medience Corporation, Tokyo, Japan) and cultured in RPMI-1640 medium supplemented with $10 \%$ fetal bovine serum (FBS) at $37^{\circ} \mathrm{C}$ in a $5 \% \mathrm{CO}_{2}$ atmosphere. Sixty-five primary ESCC tissues and corresponding noncancerous tissues were obtained from Nagoya University Hospital, all during radical esophageal resection between December 2001 and April 2012. The samples were immediately frozen in liquid nitrogen and then stored at $-80^{\circ} \mathrm{C}$ until analysis. Total RNA was obtained from these samples using the RNeasy kit (Qiagen, Hilden, Germany). None of the patients underwent preoperative treatment including chemotherapy and radiation. Specimens were classified histologically using the UICC TNM staging system for ESCC (23). Demographics, tobacco and alcohol consumption, preoperative serum tumor markers, tumor size, and pathological findings including tumor differentiation, tumor depth, vascular invasion and lymph node metastasis were obtained from the database retrospectively. Tobacco consumption was estimated using the Brinkman index, which is defined as the number of cigarettes smoked per day x smoking years. Data on alcohol consumption were obtained by questioning patients; excessive alcohol consumption was defined as alcohol intake $>210 \mathrm{~g} / \mathrm{week}$ for $\geq 3$ years (24). Median duration of patient follow-up was 33.5 months (range, 1.5-125 months). Postoperative follow-up examinations included physical examination and measurement of serum tumor markers every 3 months, and an enhanced computed tomography scan (chest and abdominal cavity) every 6 months. Adjuvant chemotherapy was administered to selected patients based on their condition and at the discretion of the physician.

Reverse transcription-polymerase chain reaction (RT-PCR) and quantitative real-time RT-PCR $(q P C R)$. The level of DENND2D mRNA expression was analyzed using RT-PCR and qPCR. Total RNA $(10 \mu \mathrm{g})$ isolated from each of the ESCC cell lines listed above, 65 primary ESCC tissues, and corresponding non-cancerous tissues were used as templates to generate complementary DNAs (cDNAs). PCR primers for DENND2D were: sense (S),5'-CACTGCTCTACCCCTTCAGC-3', in exon 7, and antisense (AS), 5'-TTTTTCATCACCAACCGACA-3', in exon 9-10, which amplified a 204-base pair (bp) product. RT-PCR amplification was performed as follows: 40 cycles at $94^{\circ} \mathrm{C}$ for $30 \mathrm{sec}, 60^{\circ} \mathrm{C}$ for $30 \mathrm{sec}$, and $72^{\circ} \mathrm{C}$ for $30 \mathrm{sec}$ after an initial denaturation step at $94^{\circ} \mathrm{C}$ for $5 \mathrm{~min}$. To confirm that equal amounts of cDNA were used as templates, RT-PCR of $\beta$-actin was performed. Each RT-PCR product was loaded directly onto $2 \%$ agarose gels, electrophoresed, stained with ethidium bromide and visualized with ultraviolet light. qPCR reactions were performed using a SYBR ${ }^{\circledR}$-Green PCR Core Reagents kit (Life Technologies, Carlsbad, CA, USA) under the following conditions: 1 cycle at $50^{\circ} \mathrm{C}$ for $2 \mathrm{~min}, 1$ cycle at $95^{\circ} \mathrm{C}$ for $10 \mathrm{~min}$, and 45 cycles at $95^{\circ} \mathrm{C}$ for $15 \mathrm{sec}$ and at $60^{\circ} \mathrm{C}$ for $30 \mathrm{sec}$. Real-time detection of the SYBR-Green emission was conducted using an ABI Prism ${ }^{\circledR} 7000$ Sequence Detection System (Life Technologies). The primers used were those described above. For standardization, glyceraldehyde-3-phosphate dehydrogenase (GAPDH) mRNA (TaqMan ${ }^{\circledR}$, GAPDH control reagents; Life Technologies) was amplified in each sample. Nine ESCC cell lines and 65 clinical samples and negative control reactions without a template were analyzed. All reactions were performed in triplicate. The amount of amplified DENND2D DNA in each sample was normalized to GAPDH. The expression of DENND2D mRNA was defined as downregulated in the tumor tissue when its level was less than one-third that of the corresponding non-cancerous tissue. Expression levels for samples are shown as DENND2D values standardized to the DENND2D/GAPDH ratio. DENND2D mRNA expression in tumor tissues and corresponding non-cancerous tissues was compared and correlated with clinicopathological characteristics and prognosis.

Analysis of the promoter region of DENND2D. The nucleotide sequence of the DENND2D promoter region was analyzed 
to determine the presence or absence of $\mathrm{CpG}$ islands, which were defined as follows: at least a 200-bp region of DNA with a high GC content $(>50 \%)$ and an observed $\mathrm{CpG} /$ expected $\mathrm{CpG}$ ratio $\geq 0.6$ (25). We used $\mathrm{CpG}$ Island Searcher software (http://cpgislands.usc.edu/) to determine the location of $\mathrm{CpG}$ islands (26).

Methylation-specific PCR (MSP). DNA samples from ESCC cell lines, ESCC tissues and corresponding non-cancerous tissues were treated with bisulfite. Briefly, $2 \mu \mathrm{g}$ of DNA was denatured with $\mathrm{NaOH}$, reacted with sodium bisulfite, and purified using the Wizard ${ }^{\circledR}$ PCR Preps DNA Purification System resin (Promega, Madison, WI, USA), treated again with $\mathrm{NaOH}$, precipitated with ethanol and resuspended in water. The sequences of the unmethylated primer pairs that amplify a 102-bp product were derived from the DENND2D promoter region upstream of exon 1 and were: S, 5'-GATATGTGTTTTTGTGGATT-3' and AS, 5'-ACACA TCCAAAACTAAAC-3'. Primer sequences derived from the DENND2D promoter region used to detect methylated DNA amplified a 193-bp product and were: S, 5'-AGG TGGCGTCGTTTAGTTTC-3' and AS, 5'-GCGAATCCG ACACTTTCACT-3'. DNA was amplified as follows: 45 cycles at $94^{\circ} \mathrm{C}$ for $30 \mathrm{sec}, 58^{\circ} \mathrm{C}$ for $30 \mathrm{sec}$ and $72^{\circ} \mathrm{C}$ for $30 \mathrm{sec}$ after an initial denaturation step at $94^{\circ} \mathrm{C}$ for $5 \mathrm{~min}$. Each PCR product was loaded directly onto $2 \%$ agarose gels, electrophoresed, stained with ethidium bromide and visualized with ultraviolet light.

Bisulfite sequence analysis. Genomic bisulfite-treated DNA from ESCC cell lines was sequenced to verify the MSP results. The sequence of the primer pair used to generate a fragment for sequencing, which was derived from the DENND2D promoter region, was: S, 5'-GGAGGTTAAGGATAGGGG-3' and AS, 5'-ACACTAACCCCCATAACC-3', which amplified a 133-bp product. DNA was amplified as follows: 50 cycles at $94^{\circ} \mathrm{C}$ for $30 \mathrm{sec}, 63^{\circ} \mathrm{C}$ for $30 \mathrm{sec}$, and $72^{\circ} \mathrm{C}$ for $30 \mathrm{sec}$ following an initial denaturation step at $94^{\circ} \mathrm{C}$ for $5 \mathrm{~min}$. PCR products were purified directly using the QIAquick PCR Purification kit (Qiagen). Purified DNA fragments were subcloned into the TA cloning vector (Life Technologies). Each DNA was mixed with $3 \mu \mathrm{l}$ of specific primer (M13) and $4 \mu \mathrm{l}$ of Cycle Sequencing Mix (BigDye ${ }^{\circledR}$ Terminator v1. 1 Cycle Sequencing kit; Life Technologies, Grand Island, NY, USA). Sequences were analyzed using an Applied Biosystems ABI 310 Prism DNA Analyzer, and sequence electropherograms were generated using ABI Sequence Analysis 3.0 software (Life Technologies).

5-aza-2'-deoxycytidine (5-aza-dC) treatment. To assess the relationship between promoter hypermethylation and DENND2D expression, ESCC cells $\left(1.5 \times 10^{6}\right)$ were treated with 5-aza-dC (Sigma-Aldrich, St. Louis, MO, USA) to inhibit DNA methylation and then cultured for 6 days with medium changes on days 1, 3 and 5. RNA was extracted and RT-PCR was performed as described above.

Immunohistochemistry (IHC). Expression and distribution of DENND2D protein were analyzed using IHC in representative cases and compared with mRNA expression patterns. Formalin-fixed, paraffin-embedded tissues were dewaxed in xylene twice for $5 \mathrm{~min}$, rehydrated in a graded alcohol series (100, 90 and 70\%), and then in $\mathrm{H}_{2} \mathrm{O}$ for 2 min each and subsequently treated with $3 \% \mathrm{H}_{2} \mathrm{O}_{2}$ to inhibit endogenous peroxidases, followed by epitope retrieval using five incubations in $10 \mathrm{mM}$ citrate buffer at $95^{\circ} \mathrm{C}, 5 \mathrm{~min}$ each. The samples were incubated with Histofine SAB-PO ${ }^{\circledR}$ (Nichirei, Tokyo, Japan) for $5 \mathrm{~min}$ to limit non-specific reactivity, and were then incubated for $1 \mathrm{~h}$ at room temperature with a rabbit antibody against DENND2D (PA5-24032; Thermo Fisher Scientific Inc., Rockford, IL, USA) diluted 1:100 in Antibody Diluent (Dako, Glostrup, Denmark). Samples were then washed with phosphate-buffered saline, followed by a 10-min incubation with a biotinylated secondary antibody (Histofine SAB-PO ${ }^{\circledR}$; Nichirei). Sections were developed for 2 min using liquid 3,3'-diaminobenzidine as the substrate (Nichirei). Staining properties were determined using surrounding hepatic veins as internal controls, and staining patterns were compared between ESCCs and the corresponding non-cancerous tissues. To avoid subjectivity, specimens were randomized and coded before analysis by two independent observers blinded to the status of the samples. Each observer evaluated all specimens at least twice within a given time interval to minimize intraobserver variation. The expression level of DENND2D protein was evaluated both in ESCC tissues and in corresponding noncancerous tissues. Tissue sections with $\geq 10 \%$ of stained cells were qualitatively defined as positive.

Statistical analysis. The relative mRNA expression levels (DENND2D/GAPDH) between ESCCs and non-cancerous tissues were analyzed using the Mann-Whitney U test. The Chi-square test was used to analyze the association between the expression and methylation status of DENND2D and clinicopathological parameters. Disease-specific and disease-free survival rates were calculated using the Kaplan-Meier method, and the difference in survival curves was analyzed using the log-rank test. We performed multivariate regression analysis to detect prognostic factors using the Cox proportional hazards model and variables with a $\mathrm{P}<0.05$ were entered into the final model. All statistical analysis was performed using JMP ${ }^{\circledR} 10$ software (SAS Institute Inc., Cary, NC, USA). A P-value of $<0.05$ was considered to indicate a statistically significant result.

\section{Results}

Patient characteristics. The mean age of the 65 patients was $64.1 \pm 7.3$ years (mean \pm standard deviation; range, $46-80$ years). The male-to-female ratio was 53:12. Fifty patients had a history of excessive alcohol consumption; 28 patients had a Brinkman index $\geq 1000$. When classified using the 7 th edition of the UICC classification, 5, 20, 30 and 10 patients were in stages I, II, III and IV, respectively.

DENND2D mRNA expression in ESCC cell lines and tumor tissues. Expression analysis of DENND2D mRNA in ESCC cell lines was performed to determine whether ESCC involved aberrant expression of DENND2D or not. The levels of DENND2D mRNA detected using qPCR were reduced compared with the median level of normal esophageal tissues in the majority of ESCC cell lines except for NUEC2 and TTn 
A

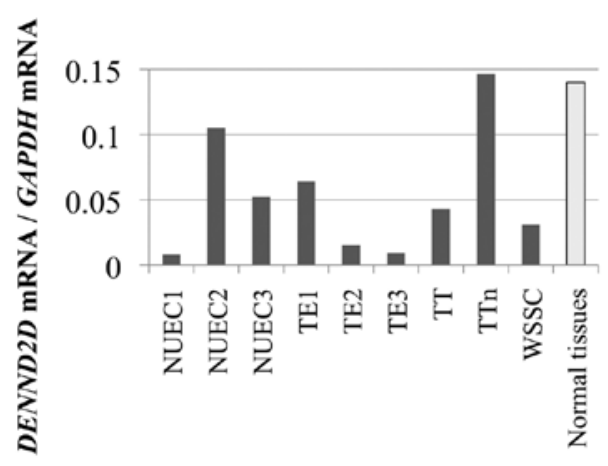

B

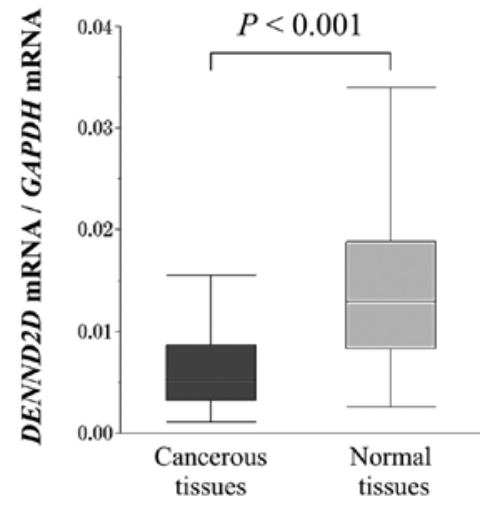

Figure 1. (A) DENND2D mRNA expression in ESCC cell lines and normal esophageal tissues using qPCR. Reduced expression was detected in all ESCC cell lines compared with controls, except for TTn. (B) The mean expression level of DENND2D mRNA was significantly lower in ESCC tissues than in corresponding normal tissues. NS, not significant.

$\mathbf{A}$

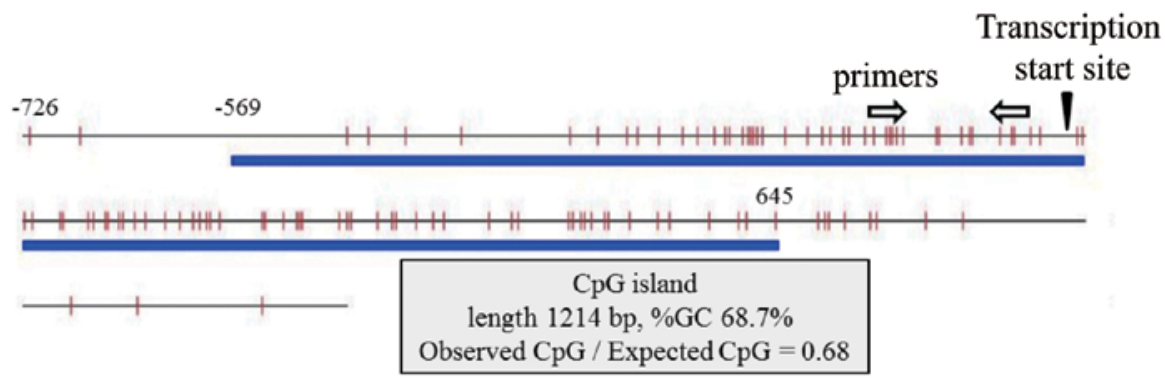

B

$\underline{N U E C 1}$ NUEC2 UM M UM M UM M UM M UM M UM M UM M UM M UM M

DENND2D

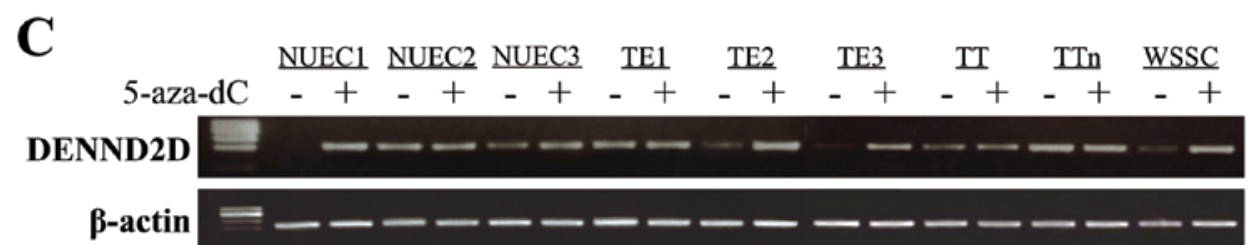

Figure 2. (A) The CpG island, indicated by the blue line, was centered on the DENND2D transcription initiation site extending upstream into the promoter region. (B) Methylation-specific PCR analysis. The DENND2D promoter was completely methylated in NUEC1 and WSSC; by contrast, methylation was partial in TE1, TE2 and TE3 cells and was not detected in NUEC2, NUEC3, TT and TTn cells. (C) RT-PCR analysis before and after 5-aza-dC treatment. Reactivation or an increase in methylation was observed if DENND2D expression was detected in NUEC1, TE2, TE3 and WSSC cells. M, methylated; UM, unmethylated.

(Fig. 1A). In particular, the DENND2D mRNA levels were 10-fold lower in NUEC1, TE2 and TE3 cells. Based on the results in ESCC cell lines, expression analysis was expanded to include clinical samples. Expression of DENND2D mRNA was significantly higher in ESCC tissues compared to corresponding normal tissues $(\mathrm{P}<0.001$; Fig. 1B).

Identification of a CpG island in the DENND2D promoter. A CpG island was identified in the DENND2D promoter region using the $\mathrm{CpG}$ Island Searcher. The properties of the CpG island were as follows: $1214 \mathrm{bp}, 68.7 \% \mathrm{GC}$ and a 0.68 observed $\mathrm{CpG} /$ expected $\mathrm{CpG}$ ratio (Fig. 2A). Therefore, we hypothesized that hypermethylation of the $\mathrm{CpG}$ islands regulated the expression of DENND2D in ESCC tissue.
MSP analysis of ESCC cell lines. MSP was conducted to verify the above hypothesis. We first determined the methylation status of DENND2D in nine ESCC cell lines. Bands consistent with methylated DNA were detected in NUEC1, TE1, TE2, TE3 and WSSC cells (Fig. 2B). We concluded that methylation of the DENND2D promoter was complete in NUEC1 and WSSC, partial in TE1, TE2 and TE3, and undetectable in NUEC2, NUEC3, TT and TTn cell lines.

Transcription of DENND2D in cells treated with 5-aza-dC. To determine whether promoter hypermethylation led to the suppression of DENND2D transcription, we analyzed ESCC cell lines before and after treatment with the DNA methylation inhibitor, 5-aza-dC. Using semi-quantitative RT-PCR, reacti- 


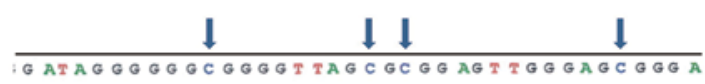

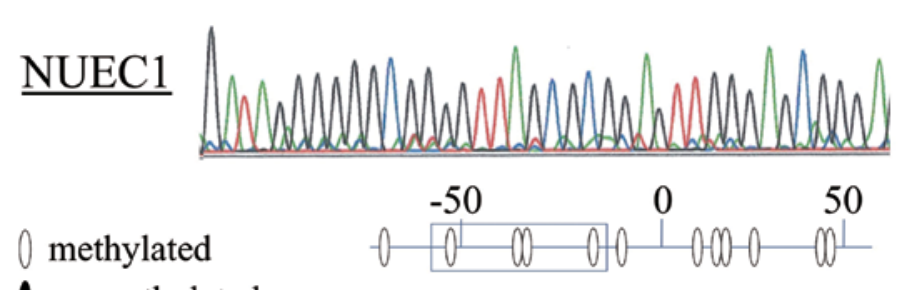

un-methylated
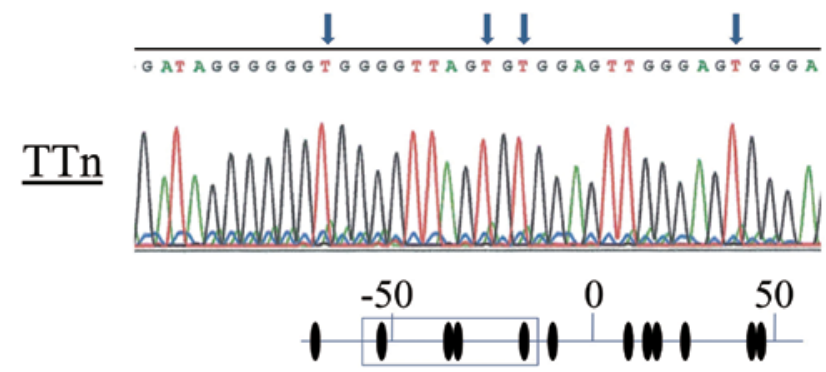

Figure 3. Bisulfite sequence analysis of genomic DNA isolated from NUEC1 and TTn cells. All CpGs in NUEC1 cells were CG and TG was present at the same position in TTn cells.

vation or an increase in DENND2D expression was detected in ESCC cell lines, which demonstrated positive MSP (Fig. 2C).

Bisulfite sequence analysis. To confirm the results of the MSP experiments, we directly sequenced the DENND2D promoter in NUEC1 (complete methylation) and TTn (undetectable methylation) cells and found that all CpGs in the NUEC1 fragment were $\mathrm{CG}$, while TG was present at the corresponding position in TTn cells (Fig. 3), thus, confirming the accuracy of our MSP data.

Prognostic value of DENND2D expression in 65 patients with ESCC. Downregulation of DENND2D mRNA was detected in tumor samples from 25/65 (38.5\%) of patients with ESCC. Patients with reduced expression of DENND2D mRNA had a significantly poorer prognosis than those without reduced expression (5-year survival rate 34.8 vs. 59.5\%; $\mathrm{P}=0.030$; Fig. 4). Patients were grouped by age, gender, preoperative symptoms, Brinkman index $(\geq 1000)$, excessive alcohol consumption, carcinoembryonic antigen $(>5 \mathrm{ng} / \mathrm{ml})$, squamous cell carcinoma-related antigen $(>1.5 \mathrm{ng} / \mathrm{ml})$, tumor size $(\geq 5.0 \mathrm{~cm})$, $\mathrm{T}$ factor (T3-4), tumor differentiation (poor), lymphatic involvement, vessel invasion, intraepithelial spread, lymph node metastasis and DENND2D mRNA expression. Of these variables, univariate analysis identified age ( $\geq 65$ years), tumor differentiation (poor), lymphatic involvement and downregulation of DENND2D mRNA as significant prognostic factors. In multivariate analysis, downregulation of DENND2D mRNA was identified as an independent prognostic factor (Hazard ratio, 2.194; $\mathrm{P}=0.039$; Table $\mathrm{I}$ ) together with age ( $\geq 65$ years), tumor differentiation (poor) and lymphatic involvement. Downregulation of DENND2D mRNA was not significantly associated with other clinicopathological parameters.

The association between DENND2D mRNA expression and clinicopathological parameters in the 65 patients is shown in Table II. Notably, downregulation of DENND2D mRNA

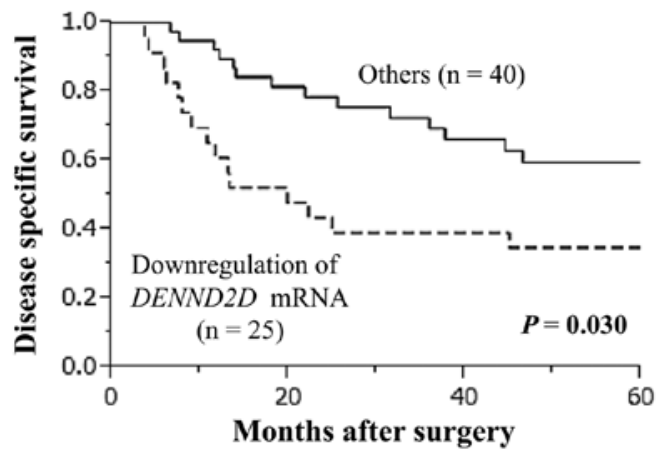

Figure 4. Kaplan-Meier survival curves for 65 patients categorized according to downregulation of DENND2D mRNA in ESCC tissues. Disease-specific survival was significantly shorter in patients without reduced expression of DENND2D (dashed line). Patients without reduced expression of DENND2D (even line). Recurrence-free survival curve.

was seen only in male patients and was significantly associated with $\mathrm{T}$ factor $(\mathrm{T} 3-4)$ and vessel invasion $(\mathrm{P}=0.033$ and $\mathrm{P}=0.038$, respectively). There was no difference in the expression level of DENND2D mRNA in non-cancerous tissues between male and female patients, indicating that DENND2D mRNA was subject to downregulation in male patients with ESCC.

Methylation status of DENND2D in 65 clinical ESCC samples. MSP analysis revealed that 42/65 (64.6\%) of ESCC tissue samples and only $2 / 65$ (3.1\%) of the corresponding noncancerous tissues showed hypermethylation of the DENND2D promoter. There was no significant association between hypermethylation of DENND2D in ESCC tissues and overall or recurrence-free survival (Table I). Promoter hypermethylation of DENND2D in ESCCs was significantly associated with downregulation of DENND2D mRNA expression $(\mathrm{P}=0.008$; Table II). 
Table I. Prognostic factors for disease-specific survival in 65 patients with squamous cell carcinoma of the esophagus.

\begin{tabular}{|c|c|c|c|c|c|c|c|}
\hline \multirow[b]{2}{*}{ Variable } & \multirow[b]{2}{*}{$\mathrm{N}$} & \multicolumn{3}{|c|}{ Univariate analysis } & \multicolumn{3}{|c|}{ Multivariate analysis } \\
\hline & & Hazard ratio & $95 \% \mathrm{CI}$ & P-value & Hazard ratio & $95 \% \mathrm{CI}$ & P-value \\
\hline Age ( $\geq 65$ years) & 28 & 2.14 & $1.05-4.44$ & $0.038^{\mathrm{a}}$ & 2.36 & $1.12-5.12$ & $0.024^{\mathrm{a}}$ \\
\hline Gender (male) & 53 & 2.13 & $0.83-7.21$ & 0.125 & & & \\
\hline Preoperative symptoms & 53 & 1.12 & $0.49-3.02$ & 0.802 & & & \\
\hline Brinkman index $(\geq 1000)$ & 28 & 1.85 & $0.91-3.81$ & 0.090 & & & \\
\hline Excessive alcohol consumption & 50 & 0.73 & $0.34-1.75$ & 0.456 & & & \\
\hline $\mathrm{CEA}(>5 \mathrm{ng} / \mathrm{ml})$ & 8 & 1.31 & $0.44-3.14$ & 0.595 & & & \\
\hline $\mathrm{SCC}(>1.5 \mathrm{ng} / \mathrm{ml})$ & 22 & 0.67 & $0.28-1.43$ & 0.312 & & & \\
\hline Tumor size $(\geq 5.0 \mathrm{~cm})$ & 39 & 0.65 & $0.32-1.34$ & 0.242 & & & \\
\hline UICC T factor (T3-4) & 48 & 1.63 & $0.74-4.10$ & 0.237 & & & \\
\hline Tumor differentiation (poor) & 11 & 2.47 & $1.03-5.34$ & $0.043^{\mathrm{a}}$ & 3.19 & $1.27-7.33$ & $0.015^{\mathrm{a}}$ \\
\hline Lymphatic involvement & 54 & 4.86 & $1.46-30.1$ & $0.007^{\mathrm{a}}$ & 5.45 & $1.58-34.3$ & $0.004^{\mathrm{a}}$ \\
\hline Vessel invasion & 26 & 1.14 & $0.55-2.31$ & 0.723 & & & \\
\hline Intraepithelial spread & 33 & 1.26 & $0.63-2.62$ & 0.508 & & & \\
\hline Lymph node metastasis & 44 & 1.78 & $0.83-4.25$ & 0.144 & & & \\
\hline Hypermethylation of $D E N N D 2 D$ & 42 & 1.09 & $0.53-2.42$ & 0.823 & & & \\
\hline Downregulation of $D E N N D 2 D$ mRNA & 25 & 2.15 & $1.05-4.37$ & $0.037^{\mathrm{a}}$ & 2.35 & $1.12-4.89$ & $0.024^{\mathrm{a}}$ \\
\hline
\end{tabular}

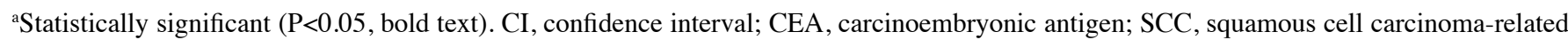
antigen; UICC, Union for International Cancer Control. Univariate analysis was performed using the log-rank test. Multivariate analysis was performed using the Cox proportional hazards model.

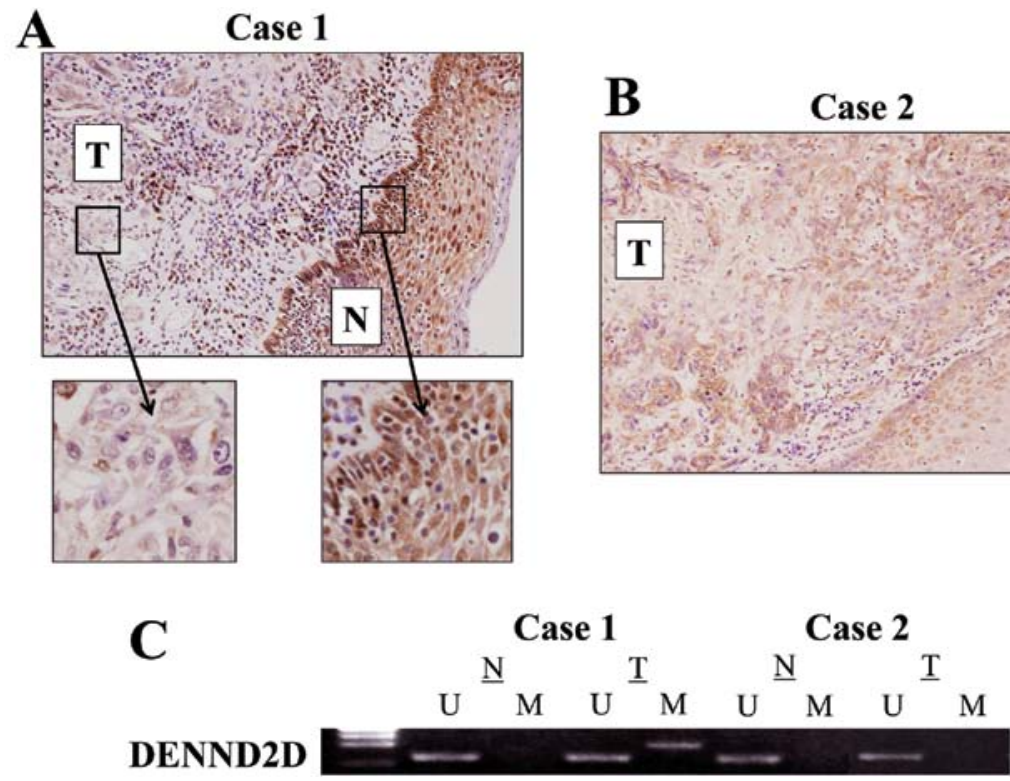

Figure 5. IHC analysis of DENND2D expression in representative ESCC cases. (A) Case 1: cancerous tissue cells showed reduced expression levels of DENND2D compared with adjacent non-cancerous tissue cells (magnification, x100). (B) Case 2: equivalent expression of DENND2D was detected in cancerous and non-cancerous tissue cells in patients without downregulation of DENND2D mRNA expression (magnification, $\mathrm{x}$ 40). (C) Methylation-specific PCR results for cases 1-2 whose IHC data are shown in A and B. N, non-cancerous tissue cells; T, tumor tissue cells; M, methylated; U, unmethylated.

IHC. The expression of DENND2D was determined using IHC in 30 cases showing relative overexpression, underexpression or equivalent DENND2D mRNA expression in ESCC tissues compared with corresponding non-cancerous tissues. A representative case with the lowest expression level of DENND2D mRNA in ESCC tissues showed reduced expression of
DENND2D in the membrane and cytoplasm of tumor cells compared with the adjacent non-cancerous tissue (Fig. 5A). By contrast, equivalent expression of DENND2D protein in tumor and normal cells was detected in a representative case without reduced DENND2D mRNA expression in the ESCC tissue (Fig. 5B). The MSP analysis of these cases is shown in Fig. 5C. 
Table II. Association between expression of DENND2D mRNA and clinicopathological parameters in 65 patients with squamous cell carcinoma of the esophagus.

\begin{tabular}{lccc}
\hline & Downregulated & & \\
& DENND2D & & \\
Clinicopathological & expression in & Other \\
parameter & tumor tissue (n) & (n) & P-value \\
\hline
\end{tabular}

Age (years)

$<65$

$\geq 65$

24

0.527

Gender

Male

Female

28

12
Preoperative symptoms

Absent

Present

Brinkman index

$<1000$

$\geq 1000$

Excessive alcohol

consumption

Absent

Present

CEA (ng/ml)

$\leq 5$

$>5$

2

$\mathrm{SCC}(\mathrm{ng} / \mathrm{ml})$

$$
\leq 1.5
$$

$>1.5$

14

Tumor size $(\mathrm{cm})$

$<5.0$

$\geq 5.0$

UICC T factor

T1-2

T3-4

Differentiation

Moderate to well

Poor

Lymphatic involvement

$$
\text { Absent }
$$

Present

Vessel invasion

Absent

Present

Intraepithelial spread

Absent

Lymph node metastasis

Absent

Present
Table II. Continued.

\begin{tabular}{lccc}
\hline & Downregulated & & \\
& DENND2D & & \\
Clinicopathological & expression in & Other & \\
parameter & tumor tissue (n) & (n) & P-value \\
\hline
\end{tabular}

Hypermethylation of DENND2D

$\begin{array}{lccc}\text { Absent } & 4 & 19 & \mathbf{0 . 0 0 8}^{\mathrm{a}} \\ \text { Present } & 21 & 21 & \end{array}$

Chi-square test. ${ }^{a}$ Statistically significant $(\mathrm{P}<0.05$, bold text). CEA, carcinoembryonic antigen; SCC, squamous cell carcinoma-related antigen; UICC, Union for International Cancer Control.

\section{Discussion}

Identification of cancer-related genes has provided an important source from which numerous prognostic biomarkers and molecular targets have been identified. In the present study, DENND2D was identified as a candidate TSG that was epigenetically inactivated in ESCC. We have shown here that the level of DENND2D mRNA expression was reduced in 8/9 ESCC cell lines and in 59/65 surgical specimens, and the mean expression level was significantly lower in cancerous tissues than in corresponding normal tissues. This result indicates that DENND2D may play an important role in the carcinogenesis of ESCC. Furthermore, the expression pattern of DENND2D using IHC was consistent with that of its mRNA levels using qPCR. Moreover, a significant reduction in DENND2D mRNA level in ESCC tissues was an independent prognostic factor. These findings suggest that DENND2D acts as a TSG and are consistent with the results of a study on DENND2D expression in lung cancer (22). Downregulation of DENND2D expression in ESCC tissues should, therefore, provide a biomarker of ESCC progression. Another striking finding was that the downregulation of DENNN2D was observed exclusively in men. The reason for the differential expression between men and women in the case of DENNN2D is unknown at this time; however, gender has been reported to influence gene expression and epigenetics $(27,28)$. Our data indicates that a unique subset of ESCC exists that is only observed in men and is associated with poor prognosis, although confirmation with a greater number of samples is required.

To understand the mechanism of regulation of DENND2D transcription, we performed methylation analysis of DENND2D after we identified a $\mathrm{CpG}$ island within its promoter. The DENND2D promoter was hypermethylated in 5/9 ESCC cell lines, and DENND2D transcription could be reactivated in cells treated with an inhibitor of methylation. Hypermethylation was frequently detected (64.6\%) in ESCC tissues and significantly associated with substantial (3 times or more) reduction of DENND2D mRNA levels. Therefore, we consider promoter hypermethylation as a potent regulatory factor of DENND2D transcription in ESCC.

The DENND2 family is the only example where the DENN domain is located within the C-terminal region $(20,29)$. Each 
DENND2 protein acts as a GEF for Rab9a/b. DENND2D is composed of a DENN domain alone (30); therefore, the DENN domain mediates GEF activity. Rab GTPases regulate tumorigenesis via trafficking-mediated events and some function in a trafficking-independent manner $(15,31,32)$. Additionally, it is known that several members of the Rab GTPase family affect exosome secretion via the trans-Golgi network or by inducible vesicular trafficking (33-35). Exosomes released from cancer cells can be taken up by neighboring cells and are capable of inducing pathways involved in cancer initiation and progression (36). Therefore, it is thought that DENND2D, which is a regulator of Rab GTPases, plays an important role in carcinogenesis and cancer progression.

The present study was limited by its lack of sufficient functional analysis of DENND2D, which tempers the conclusion that it acts as a tumor suppressor in ESCC. Further studies are required to clarify the molecular mechanisms underlying the biological activities and effects that DENND2D has on chemoresistance in ESCC.

In summary, we propose DENND2D as a candidate TSG that is inactivated by promoter hypermethylation in ESCC and shows promise as a novel biomarker of progression of ESCC.

\section{References}

1. Ferlay J, Shin H, Bray F, Forman D, Mathers C and Parkin D: Estimates of worldwide burden of cancer in 2008: GLOBOCAN 2008. Int J Cancer 127: 2893-2917, 2010.

2. Siegel R, Ward E, Brawley O and Jemal A: Cancer statistics, 2011: the impact of eliminating socioeconomic and racial disparities on premature cancer deaths. CA Cancer J Clin 61: 212-236, 2011.

3. Kamangar F, Dores GM and Anderson WF: Patterns of cancer incidence, mortality, and prevalence across five continents: defining priorities to reduce cancer disparities in different geographic regions of the world. J Clin Oncol 24: 2137-2150, 2006.

4. Kanda M, Nomoto S, Nishikawa Y, Sugimoto H, Kanazumi N, Takeda $S$ and Nakao A: Correlations of the expression of vascular endothelial growth factor B and its isoforms in hepatocellular carcinoma with clinico-pathological parameters. J Surg Oncol 98: 190-196, 2008

5. Kanda M, Nomoto S, Okamura Y, Hayashi M, Hishida M, Fujii T, Nishikawa Y, Sugimoto H, Takeda S and Nakao A: Promoter hypermethylation of fibulin 1 gene is associated with tumor progression in hepatocellular carcinoma. Mol Carcinog 50: 571-579, 2011.

6. Kanda M, Nomoto S, Okamura Y, Nishikawa Y, Sugimoto H, Kanazumi N, Takeda S and Nakao A: Detection of metallothionein $1 \mathrm{G}$ as a methylated tumor suppressor gene in human hepatocellular carcinoma using a novel method of double combination array analysis. Int J Oncol 35: 477-483, 2009.

7. Wang YN, Yamaguchi H, Hsu JM and Hung MC: Nuclear trafficking of the epidermal growth factor receptor family membrane proteins. Oncogene 29: 3997-4006, 2010.

8. Casas A, Di Venosa G, Hasan T and Al Batlle: Mechanisms of resistance to photodynamic therapy. Curr Med Chem 18: 2486-2515, 2011

9. Stenmark H: Rab GTPases as coordinators of vesicle traffic. Nat Rev Mol Cell Biol 10: 513-525, 2009.

10. Pawson T and Nash P: Assembly of cell regulatory systems through protein interaction domains. Science 300: 445-452, 2003.

11. Marat AL and McPherson PS: The connecdenn family, Rab35 guanine nucleotide exchange factors interfacing with the clathrin machinery. J Biol Chem 285: 10627-10637, 2010.

12. Sato M, Sato K, Liou W, Pant S, Harada A and Grant BD: Regulation of endocytic recycling by $C$. elegans Rab35 and its regulator RME-4, a coated-pit protein. EMBO J 27: 1183-1196, 2008.

13. Levivier E, Goud B, Souchet M, Calmels TP, Mornon JP and Callebaut I: uDENN, DENN, and dDENN: indissociable domains in Rab and MAP kinases signaling pathways. Biochem Biophys Res Commun 287: 688-695, 2001.
14. Pfeffer S: A model for Rab GTPase localization. Biochem Soc Trans 33: 627-630, 2005.

15. Subramani D and Alahari SK: Integrin-mediated function of Rab GTPases in cancer progression. Mol Cancer 9: 312, 2010.

16. Cheng KW, Lahad JP, Kuo WL, Lapuk A, Yamada K, Auersperg N, Liu J, Smith-McCune K, Lu KH, Fishman D, Gray JW and Mills GB: The RAB25 small GTPase determines aggressiveness of ovarian and breast cancers. Nat Med 10: 1251-1256, 2004.

17. Rink J, Ghigo E, Kalaidzidis Y and Zerial M: Rab conversion as a mechanism of progression from early to late endosomes. Cell 122: 735-749, 2005.

18. Girard M, Allaire PD, McPherson PS and Blondeau F: Non-stoichiometric relationship between clathrin heavy and light chains revealed by quantitative comparative proteomics of clathrin-coated vesicles from brain and liver. Mol Cell Proteomics 4: 1145-1154, 2005.

19. Majidi M, Hubbs AE and Lichy JH: Activation of extracellular signal-regulated kinase 2 by a novel Abl-binding protein, ST5. J Biol Chem 273: 16608-16614, 1998.

20. Marat AL, Dokainish H and McPherson PS: DENN domain proteins: regulators of Rab GTPases. J Biol Chem 286: 13791-13800, 2011.

21. Postel EH, Weiss VH, Beneken J and Kirtane A: Mutational analysis of NM23-H2/NDP kinase identifies the structural domains critical to recognition of a c-myc regulatory element. Proc Natl Acad Sci USA 93: 6892-6897, 1996.

22. Ling B, Zheng H, Fu G, Yuan J, Shi T, Chen S, Liu Y, Liu Y, Cao Y, Zheng S, Guo S, Han N, Gao Y, Cheng S and Zhang K: Suppression of non-small cell lung cancer proliferation and tumorigenicity by DENND2D. Lung Cancer 79: 104-110, 2013.

23. International Union Against Cancer: TNM Classification of Malignant Tumors. 7th edit. Sobin LH, Gospodarowicz MK and Wittekind C (eds). Wiley-Blackwell, New York, 2009.

24. Long MJ, Jiang CQ, Lam TH, Lin JM, Chan YH, Zhang WS, Jin YL, Liu B, Thomas GN and Cheng KK: Alcohol consumption and electrocardiographic left ventricular hypertrophy and mediation by elevated blood pressure in older Chinese men: The Guangzhou Biobank Cohort Study. Alcohol 47: 473-480, 2013.

25. Takai D and Jones PA: Comprehensive analysis of CpG islands in human chromosomes 21 and 22. Proc Natl Acad Sci USA 99: 3740-3745, 2002.

26. Takai D and Jones PA: The CpG island searcher: a new WWW resource. In Silico Biol 3: 235-240, 2003.

27. Kiyohara C, Wakai K, Mikami H, Sido K, Ando M and Ohno Y: Risk modification by CYP1A1 and GSTM1 polymorphisms in the association of environmental tobacco smoke and lung cancer: a case-control study in Japanese nonsmoking women. Int J Cancer 107: 139-144, 2003

28. Mollerup S, Ryberg D, Hewer A, Phillips DH and Haugen A: Sex differences in lung CYP1A1 expression and DNA adduct levels among lung cancer patients. Cancer Res 59: 3317-3320, 1999.

29. Bloethner S, Mould A, Stark M and Hayward NK: Identification of ARHGEF17, DENND2D, FGFR3, and RB1 mutations in melanoma by inhibition of nonsense-mediated mRNA decay. Genes Chromosomes Cancer 47: 1076-1085, 2008.

30. Yoshimura S, Gerondopoulos A, Linford A, Rigden DJ and Barr FA: Family-wide characterization of the DENN domain Rab GDP-GTP exchange factors. J Cell Biol 191: 367-381, 2010.

31. Croizet-Berger K, Daumerie C, Couvreur M, Courtoy PJ and van den Hove MF: The endocytic catalysts, Rab5a and Rab7, are tandem regulators ofthyroid hormone production. Proc Natl Acad Sci USA 99: 8277-8282, 2002.

32. Cheng KW, Lahad JP, Gray JW and Mills GB: Emerging role of RAB GTPases in cancer and human disease. Cancer Res 65: 2516-2519, 2005.

33. Ponnambalam S and Baldwin SA: Constitutive protein secretion from the trans-Golgi network to the plasma membrane. Mol Membr Biol 20: 129-139, 2003.

34. Loomis RJ, Holmes DA, Elms A, Solski PA, Der CJ and Su L: Citron kinase, a RhoA effector, enhances HIV-1 virion production by modulating exocytosis. Traffic 7: 1643-1653, 2006.

35. Ostrowski M, Carmo NB, Krumeich S, Fanget I, Raposo G, Savina A, Moita CF, Schauer K, Hume AN, Freitas RP, Goud B, Benaroch P, Hacohen N, Fukuda M, Desnos C, Seabra MC, Darchen F, Amigorena S, Moita LF and Thery C: Rab27a and Rab27b control different steps of the exosome secretion pathway. Nat Cell Biol 12: 19-30, 2010.

36. Henderson MC and Azorsa DO: The genomic and proteomic content of cancer cell-derived exosomes. Front Oncol 2: 38, 2012. 